\title{
KONDISI LAHAN KEBUN TEBU SETELAH PANEN DAN KARAKTERISTIK FISIK DAN MEKANIK SERASAH TEBUNYA
}

\author{
THE SUGAR CANE PLANTATION OF LAND CONDITION AFTER \\ HARVESTING AND MECHANICS AND PHYSICAL CHARACTERISTICS
}

\author{
Wahyu K Sugandi' ${ }^{1}$ I Nengah Suastawa ${ }^{2)}$, Joko Wiyono ${ }^{3)}$ \\ ${ }^{1)}$ Departemen Teknik Pertanian dan Biosistem FTIP Unpad \\ ${ }^{2)}$ Departemen Teknik Mesin dan Budidaya Pertanian IPB \\ ${ }^{3)}$ Balai Besar Pengembangan Mekanisasi Pertanian \\ "Komunikasi penulis, Email : sugandiwahyu@gmail.com
}

Naskah ini diterima pada 10 Oktober 2017; revisi pada 28 Novmber 2017; disetujui untuk dipublikasikan pada 13 Desember 2017

\begin{abstract}
Nowadays, burning sugar cane before and after harvest can be damaged the environment and disturb human health in the environment of sugar cane plantations. The efforts to handle the amount of sugarcane which disrubts the process of sugarcane cultivation has been begining. One of them was enumerating the sugarcane became a small size to use as compost, or immersed in the soil. The process was designing machines related to the handling of sugarcane requires data supporting the physical and mechanical properties of sugarcane. The data will be very helpful in generating the design machines that are effective and efficient both technically and economically. The methods this research was descriptive analysis that is doing measurement and data analysis to know condition of land and characteristic of sugarcane. The research results showed that the width of $120 \mathrm{~cm}$ ground bunds, the plant distance was $120 \mathrm{~cm}$ and the height of the bundle was $20 \mathrm{~cm}$. Density of Kamba $7.7 \mathrm{~kg} /$ $\mathrm{cm}^{3}$ of sugarcane: average length of shoots $162.5 \mathrm{~cm}$, average number of leaves per shoot 4.1 sheets, leaf width average $5.0 \mathrm{~cm}$, average leaf thickness $0.3 \mathrm{~mm}$, flat shoot base diameter $21.3 \mathrm{~mm}$, and shoot weight of 57.3 grams. leaf length $161.1 \mathrm{~cm}$, leaf base width $4.4 \mathrm{~cm}$, middle width of leaves $4.1 \mathrm{~cm}$, leaf tip width $3.9 \mathrm{~cm}$, leaf thickness $0.3 \mathrm{~mm}$, and leaves weight 8.9 grams.
\end{abstract}

Keywords: Physical properties, mechanical properties, sugarcane.

\begin{abstract}
ABSTRAK
Telah disadari belakangan ini bahwa pembakaran tebu sebelum dan setelah panen dapat merusak lingkungan hidup serta mengganggu kesehatan manusia di lingkungan perkebunan tebu. Usaha-usaha untuk menangani serasah tebu yang jumlahnya sangat banyak, yang mengganggu proses budidaya tebu telah mulai dilakukan. Salah satunya adalah mencacah serasah tebu menjadi ukuran kecil untuk digunakan sebagai kompos, atau dibenamkan kembali ke dalam tanah. Proses perancangan alat atau mesin yang berkaitan dengan penanganan serasah tebu tersebut membutuhkan data pendukung sifat fisik dan mekanik serasah tebu. Data tersebut akan sangat membantu dalam menghasilkan rancangan alat dan mesin yang efektif dan efisien baik secara teknis maupun ekonomis. Metode Penelitian ini adalah analisis deskriptif yaitu melakukan pengukuran dan analisis data untuk mengetahui kondisi lahan dan karakteristik dari serasah tebu. Hasil Penelitian menunjukkan bahwa lebar guludun $120 \mathrm{~cm}$, jarak tanaman $120 \mathrm{~cm}$ dan tinggi guludan $20 \mathrm{~cm}$. Kerapatan Kamba serasah tebu 7,71 kg/ $\mathrm{cm}^{3}$, : panjang rata-rata pucuk $162.5 \mathrm{~cm}$, jumlah rata-rata daun per pucuk 4.1 lembar, lebar daun rata-rata $5.0 \mathrm{~cm}$, tebal daun rata-rata $0.3 \mathrm{~mm}$, diameter pangkal pucuk rata-rata $21.3 \mathrm{~mm}$, dan berat pucuk 57.3 gram. panjang daun $161.1 \mathrm{~cm}$, lebar pangkal daun $4.4 \mathrm{~cm}$, lebar tengah daun $4.1 \mathrm{~cm}$, lebar ujung daun $3.9 \mathrm{~cm}$, tebal daun $0.3 \mathrm{~mm}$, dan berat daun 8.9 gram.
\end{abstract}

Kata kunci: Sifat fisik, sifat mekanik, serasah tebu 


\section{PENDAHULUAN}

Tebu merupakan tanaman utama penghasil gula yang merupakan komoditi pangan penting baik untuk dikonsumsi langsung maupun untuk keperluan industri di Indonesia. Pada tahun 1930-an Jawa pernah sebagai exportir gula terbesar di dunia, namun saat ini kita selalu kekurangan gula. Gula adalah komoditi strategis setelah BBM dan beras, masih memiliki ketergantungan terhadap impor walaupun sejak tahun 2013 luas lahan perkebunan tebu telah meningkat dari 335 ribu hektar menjadi lebih dari 451 ribu hektar pada tahun 2016 (Ditjenbun 2016). Konsumsi gula nasional sebesar sekitar 5 juta ton per tahun masih belum bisa dipenuhi oleh industri gula dalam negeri. Dari gambaran di atas masih banyak perbaikan teknologi yang harus dilakukan untuk dapat merevitalisasi industri gula nasional, khususnya di bidang on farm perkebunan tebu.

Pembakaran tebu sebelum panen di Pulau Jawa tidak diijinkan karena umumnya berdekatan dengan pemukiman penduduk. Kondisi ini mengakibatkan pada saat habis panen, banyak serasah tebu dan sebagian kecil batang tebu yang masih tersisa di lahan. Serasah tebu hasil tebangan sangat bulky berupa pucuk, batang, sisa daun, dongkelan, sogolan dan akar. Sebagai akibatnya untuk memudahkan penyiapan lahan plant cane atau pekerjaan pemeliharaan tanaman ratoon maka dilakukan pembakaran serasah hasil sisa tebangan di lahan seperti yang disajikan pada Gambar 1.

Serasah hasil tebangan di lahan tebu dapat mencapai 20-25 ton /ha (Toharisman 1991).
Jika dibakar maka serasah yang jumlahnya sangat besar tersebut hanya terbuang sia-sia, padahal jika serasah tersebut dapat dicacah dan dibenamkan ke dalam tanah maka dapat diharapkan menjadi pupuk organik bagi tanah.

Mengingat luasnya areal kebun tebu, kegiatan pencacahan dan pembenaman serasah ke dalam tanah hanya mungkin dilakukan dengan mekanisasi. Kegiatan mekanisasi ini hanya bisa dilakukan apabila ada mesin pengumpul, pencacah dan pembenam serasah. Spesifikasi mesin juga harus memenuhi kebutuhan dan kondisi budidaya tebu di Indonesia. Mengingat belum tersedianya alat maupun mesin tersebut, maka perlu untuk mempelajari aspek pencacahan dan pembenaman serasah tebu, merancang dan membuat mesinnya. Perrson (1987) mendefinisikan pemotongan sebagai suatu proses pemisahan secara mekanik suatu benda padat di sepanjang garis yang sebelumnya telah ditentukan dengan menggunakan alat pemotong. Pemotongan (Cutting) bahan bahan pertanian merupakan salah satu kegiatan yang paling sering dilakukan, misalnya pada saat panen (harvesting), dalam pemisahan (separation) dan juga dalam proses pengecilan ukuran bahan (size reduction).

Pada saat pemotongan mata pisau menembus ke dalam bahan, melewati kekuatan bahan sehingga bahan menjadi terpisah. Pada saat pemotongan berlangsung, terjadi perbedaan deformasi pada bahan, yang tergantung pada bentuk mata pisau dan proses kinematik pemotongan dan kinematika pemotongan Pada Gambar 2 memperlihatkan bentuk - bentuk pemotongan yang umum dilakukan. Pada

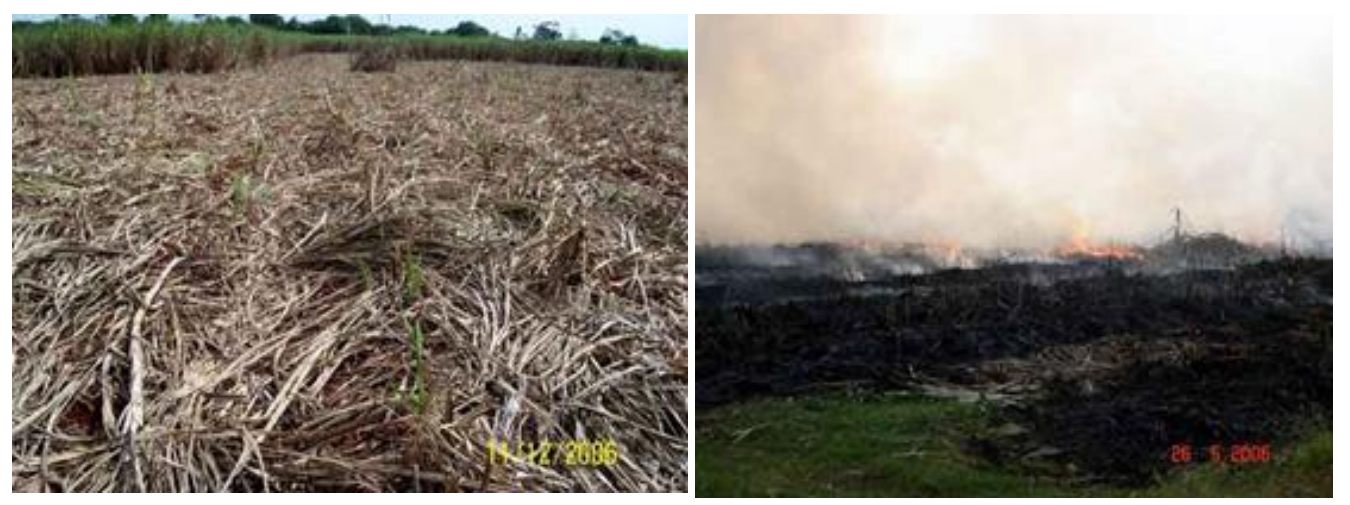

Gambar 1. Kondisi serasah tebu di lahan(kiri) dan pembakaran serasah sebelum olah tanah (kanan) 


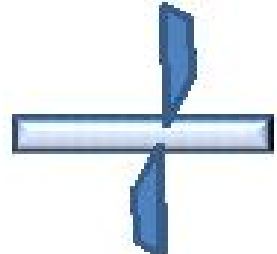

(a)

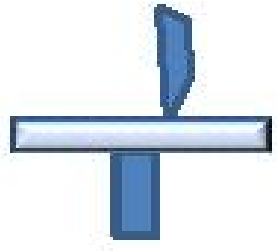

(b)

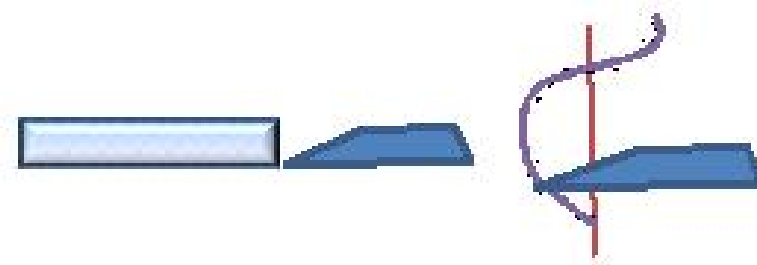

(c) (d)

Gambar 2. Beberapa mekanisme pemotongan

gambar 2a) memperlihatkan proses pemotongan yang menggunakan dua mata pisau yang saling berhadapan dan terlibat pemotongan (countermoving blade) contoh untuk kasus ini adalah gunting. Gambar $2 \mathrm{~b}$ ) memperlihatkan tipe alat potong dimana bahan diletakkan pada landasan yang diam dan pisau pemotongan bergerak, contoh praktis pada proses ini adalah pada perajangan keripik singkong dengan alat chipper. Gambar 2c) mengilustrasikan pemotongan lapisan yang tipis, dimana distribusi tegangan disekitar mata pisau mengalami distorsi yang sangat besar akibat permukaan bebas pada sekitar bidang pemotongan. Gambar d) menunjukkan metode pemotongan yang saat ini banyak dilakukan. Pada kasus ini kecepatan mata pisau harus tinggi $(20-40 \mathrm{~m} / \mathrm{s}$ ) (Perrson, 1987).

Bahan dapat dipotong secara individu atau kelompok (bundle) tergantung pada jenis bahan dan teknik proses pengolahan yang dilakukan. Contoh pemotongan secara kelompok adalah pertama - pertama bahan ditekan dan terdeformasi dengan mata pisau tergantung pada bentuk dan kecepatan baru kemudian diikuti dengan pemotongan. Mata pisau dapat bergerak secara normal ke bahan yang dipotong atau bergerak dengan sudut tertentu.

Agar dapat menganlisa mekanisme pencacahan, pengaliran, penjepitan serasah tebu, mendapatkan parameter teknis pemotongan yang paling efektif dan efisien, maka sangat penting untuk diketahui secara pasti tentang sifat-sifat fisik maupun mekanik dari serasah tebu di lapangan maupun secara individu. Penelitian ini bertujuan untuk memperlajari Karakteristik fisik (bentuk, ukuran, warna, berat jenis) dan sifat mekanik (perubahan akibat tekanan dalam kondisi bulk) serasah tebu utama yaitu daun tebu kering dan pucuk tebu kering yang ditemukan di lapangan 4-7 hari setelah panen.

\section{METODOLOGI PENELITIAN}

Penelitian ini dilakukan di Kebun tebu PG Subang, Jawa Barat dan Laboratorium Alat dan Mesin Pertanian FTIP Unpad. Alat dan Bahan uang digunakan adalah Serasah tebu berupa daun, pucuk dan batang tebu kering sebanyak 100 sample yang diperoleh dari PG Subang Jawa Barat. Alat yang dipergunakan dalam percobaan ini adalah meteran, jangka sorong, timbangan, oven, relief meter. Metode Penelitian ini adalah analisis deskriptif yaitu melakukan pengukuran dan analisis data untuk mengetahui kondisi lahan dan karakteristik dari serasah tebu.

\subsection{Pengumpulan Data Serasah}

\subsubsection{Pengukuran Karakteristik fisik tebu}

Pengukuran karekteristik fisik tebu yang dilakukan terdiri dari dimensi serasah tebu, bulk density, kadar air, elastisitas dan profil guludan pada lahan tebu Data-data pengukuran tersebut sangat penting terutama dalam menganalisis

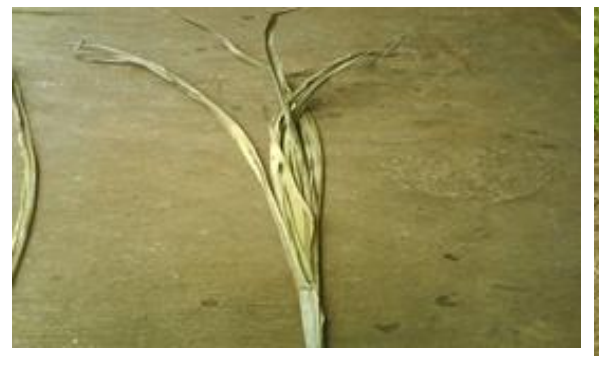

Serasah pucuk tebu

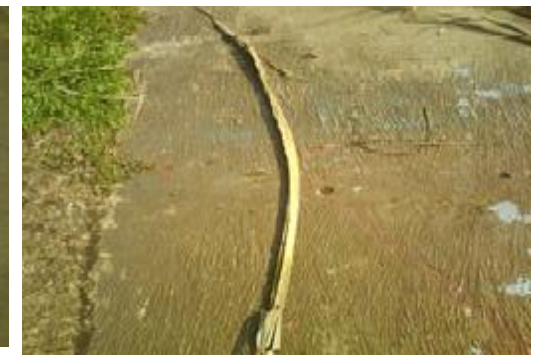

Serasah daun tebu 
desain unit pencacah dari mesin pencacah serasah tebu. Adapun metode yang digunakan dalam pengukuran karakteristik serasah tebu adalah dengan cara melakukan pengukuran langsung dengan alat ukur yaitu mistar, jangka sorong dan timbangan digital. Jumlah data yang diukur untuk daun dan pucuk tebu adalah 100 data.

\subsection{Pengukuran kerapatan isi (bulk density)} Pengukuran kerapatan isi serasah tebu dilakukan langsung di lahan tebu. Hal ini dilakukan untuk mengetahui kondisi lahan sebenarnya karena desain mesin serasah tebu akan diaplikasikan pada lahan tebu. Pengambilan sampel tumpukan serasah dilakukan pada luasan $2 \times 2$ meter secara acak. Alat yang digunakan adalah patok, meteran dan timbangan gantung. Pengukuran ini dilakukan secara acak pada berbagai lahan. Pengukuran dilakukan pada 10 titik pengukuran berbeda. Situasi pengukuran dapat dilihat pada Gambar 3.

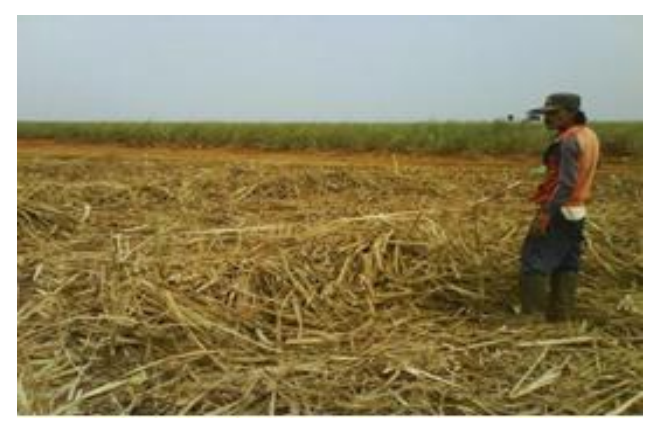

Gambar 3. Pengukuran serasah tebu di lahan

\subsection{Metode pengukuran kadar air bahan}

Kadar air serasah tebu berfungsi untuk mengetahui kandungan air yang terdapat pada serasah setelah pemanenan. Varietas tanaman tebu yang digunakan adalah PS 865 langsung diambil di perkebunan tebu - PG Subang 1 minggu setelah panen. Pengukuran kadar air dilakukan dengan cara metode gravimetrik yaitu dengan menimbang berat bahan serasah berupa daun, pucuk dan tebu setelah pemanenan, setelah ditimbang selanjutnya bahan tersebut dimasukkan kedalam oven denganm suhu $100^{\circ} \mathrm{C}$ lalu ditimbang ulang.

\subsection{Pengukuran Elastisitas}

Elastisitas dilakukan dengan cara menekan serasah tebu dengan beban hingga ketinggian tertentu beban yang diberikan adalah $80 \mathrm{~kg}$ dan $50 \mathrm{~kg}$ dengan luas penampang $448 \mathrm{~cm}^{2}$ sebanyak 20 kali. Pengukuran ketinggian serasah sebelum dan sesudah ditekan di catat sehingga rasio perbandingan pemadatan dapat diperoleh.

\subsection{Pengukuran profil guludan lahan tebu}

Pengukuran profil guludan di lahan sangat diperlukan untuk menentukan dimensi dari rancangan mesin yang akan dibuat. Adapun alat yang digunakan pada saat pengukuran di lahan adalah relief meter, water pas dan penggaris.

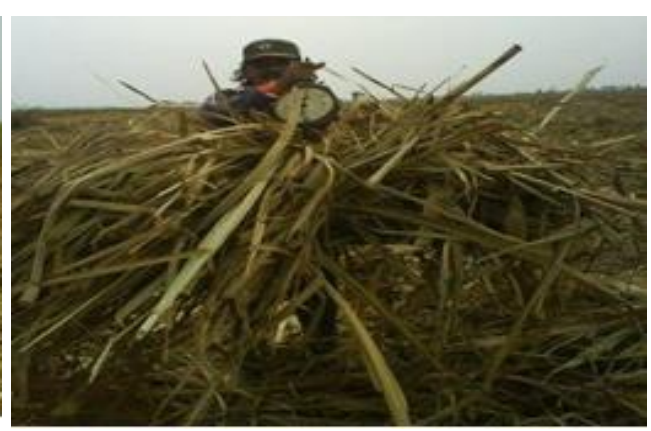

Mekanisme pengukuran dilakukan dengan cara memasang relief meter pada lahan guludan tebu yang dilengkapi dengan water pas dengan tujuan agar posisi relief meter dalam posisi lurus seimbang (Gambar 4). Setelah mendapatkan posisi lurus dan seimbang langkah selanjutnya lebar guludan, ketinggian guludan dan jarak antar tanaman diukur menggunakan penggaris.

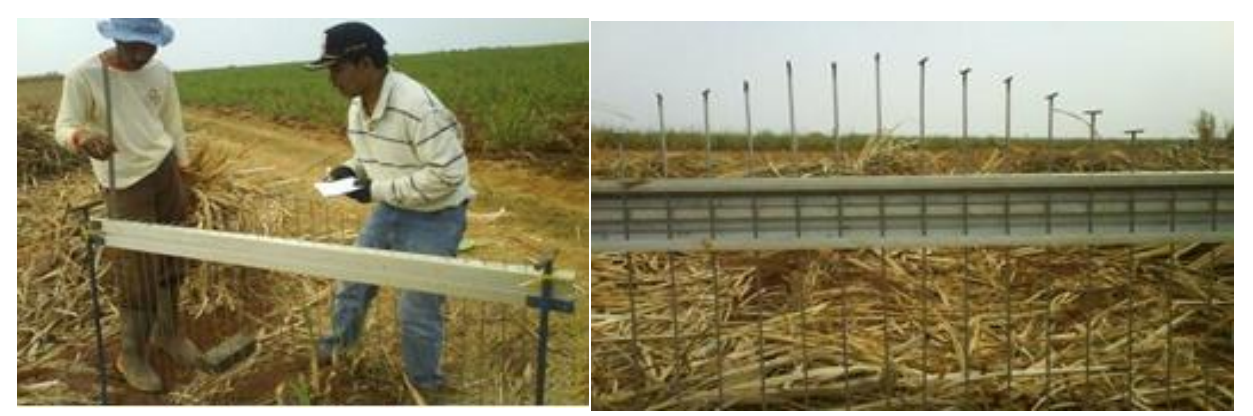

Gambar 4. Pengukuran profil guludan di PG Subang menggunakan reliefmeter 


\section{HASIL DAN PEMBAHASAN}

\subsection{Kondisi lahan}

Berdasarkan hasil survey lapangan di PG. Subang, Jawa barat, PG Subang menerapkan sistim tebang 2-2 dan 4-2 dengan harapan untuk mempermudah dalam pembersihan dan pengangkutan. Sistem penebangan yang diterapkan di PG Subang dikatakan sebagai sistem tebang 4-2 atau sistem tebang 2-2

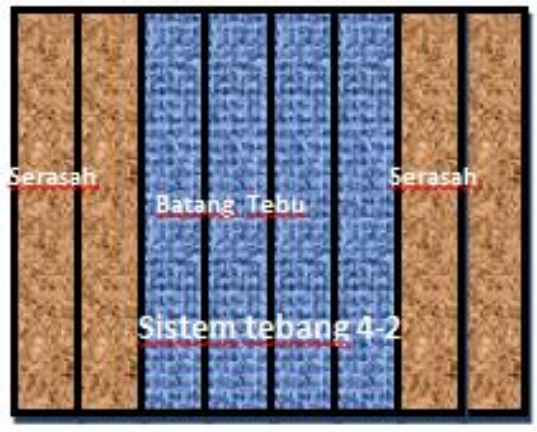

Gambar 5. Sistem tebang tebu di PG. Subang

(Gambar 5). Sistem tebang yang biasa dilakukan adalah 4-2, sedangkan untuk sistem 2-2 biasanya untuk lahan yang sulit seperti banyak tebu yang roboh atau tebu yang melilit. Sistem tebang 4-2 artinya adalah empat juring atau barisan digunakan sebagai tempat meletakkan batang tebu hasil panen, dan 2 juring di sebelah empat jurung tersebut menjadi tempat meletakkan sampah tebu berupa pucuk dan daun tebu yang disebut trash atau serasah. Begitu juga untuk sistem 2-2 hanya bedanya jumlah barisan tebu bersihnya hanya 2 barisan. Tujuan dari penerapan sistem 4-2 yaitu untuk menekan tunggak dan mempermudah dalam pembersihan lahan.

Solusi sementara saat ini serasah tersebut dibakar dengan pengawasan yang cukup ketat oleh pihak pabrik karena belum ditemukan cara penanganan dan pemanfaatan serasah yang lebih efektif dan efesien.

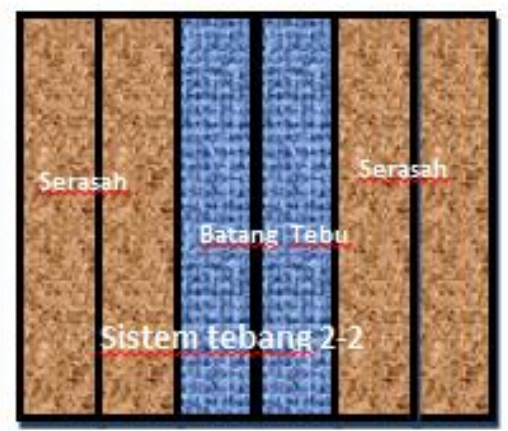

\subsection{Karakteristik Fisik SerasahTebu}

Dari hasil pengukuran terhadap daun dan pucuk tebu diperoleh data - data seperti pada Tabel 1. Dari data tersebut diperoleh lebar rata - rata daun adalah $4.12 \mathrm{~cm}$ Sedangkan data hasil pengukuran terhadap pucuk tebu dengan metode pengukuran yang sama adalah seperti pada Tabel 2 .

Data tersebut di atas diperlukan khususnya dalam mendesain unit pencacah serasah tebu dan alat pengujian torsi karena tebal pucuk ada yang $0.2 \mathrm{~cm}(2 \mathrm{~mm})$ maka jarak antara pisau pemotong pucuk tidak boleh lebih dari $2 \mathrm{~mm}$.

Tabel 1. Karakteristik fisik daun tebu

\begin{tabular}{lccc}
\hline \multicolumn{1}{c}{ Karakteristik } & Rata - rata & Kisaran & Simpangan baku \\
\hline Panjang daun & $161.51 \mathrm{~cm}$ & $117-195 \mathrm{~cm}$ & 14.45 \\
Lebar posisi tepi daun & $4.38 \mathrm{~cm}$ & $3.0-6.0 \mathrm{~cm}$ & 0.8 \\
Lebar posisi tengah daun & $4.08 \mathrm{~cm}$ & $2.8-5.6 \mathrm{~cm}$ & 0.67 \\
Lebar posisi ujung daun & $3.89 \mathrm{~cm}$ & $2.9-5.3 \mathrm{~cm}$ & 0.65 \\
Tebal daun & $0.25 \mathrm{~cm}$ & $0.25 \mathrm{~cm}$ & 0 \\
Berat daun & $8.90 \mathrm{gram}$ & $3.5-13 \mathrm{gram}$ & 1.78 \\
\hline
\end{tabular}

Tabel 2. Karakteristik fisik pucuk tebu

\begin{tabular}{lccc}
\hline \multicolumn{1}{c}{ Karakteristik } & Rata - rata & Kisaran & Simpangan baku \\
\hline Panjang pucuk & $162.54 \mathrm{~cm}$ & $130-190 \mathrm{~cm}$ & 11.6 \\
Jumlah daun & $4 \mathrm{unit}$ & $3.0-6.0 \mathrm{unit}$ & 0.8 \\
Lebar pucuk & $5.02 \mathrm{~cm}$ & $4.0-6.0 \mathrm{~cm}$ & 0.74 \\
Diameter pucuk & $21.34 \mathrm{~mm}$ & $15.3-32.3 \mathrm{~mm}$ & 3.64 \\
Tebal pucuk & $0.35 \mathrm{~cm}$ & $0.2-0.5 \mathrm{~cm}$ & 0.06 \\
Berat pucuk & $57.35 \mathrm{gram}$ & $29.0-98.1 \mathrm{gram}$ & 14.87 \\
\hline
\end{tabular}




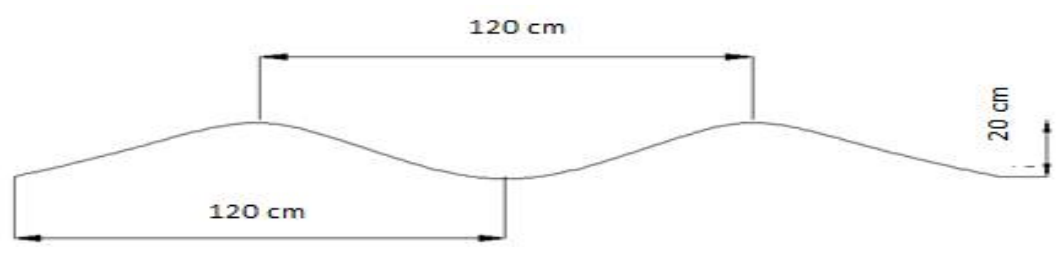

Gambar 6 Profil guludan di perkebunan tebu - PG Subang Jawa Barat.

\subsection{Kerapatan Isi (Bulk Density) Serasah Tebu}

Pengukuran kerapatan isi (bulk density) serasah tebu dilakukan langsung di lahan tebu. Berdasarkan hasil pengukuran rata-rata tinggi tumpukan serasah tebu di lahan adalah 0.36 meter, dan memiliki kerapatan isi rata-rata 7.7 $\mathrm{kg} / \mathrm{m}^{3}$. Ketinggian tumpukan ini sebagai dasar dalam mendisain unit pengambilan serasah tebu. Sementara, kerapatan isi akan sangat mempengaruhi mekanisme pengangkatan, pengaliran serasah menuju bagian penjepit dan akhirnya sampai pada bagian pencacah. Data tersebut juga bermanfaat untuk menentukan bentuk dan ukuran unit pengumpan dan unit pencacah serasah tebu.

\subsection{Kadar Air Serasah Tebu}

Hasil pengukuran dan perhitungan mengenai kadar air serasah tebu pada basis kering menunjukan bahwa rata - rata kadar air batang adalah $84.1 \%$, rata - rata kadar air pucuk adalah $15.7 \%$, dan rata - rata kadar air daun adalah $16.9 \%$

\subsection{Elastisitas Serasah Tebu}

Serasah tebu yang tersebar di lahan bersifat bulky dan berrongga sehingga memungkinkan untuk dipadatkan. Berdasarkan hasil pengukuran serasah tebu dapat dipadatkan hingga 4 kali. Hal ini sebagai dasar pertimbangan untuk desain silinder penjepit dan pengujian pemadatan.

\subsection{Profil Guludan Lahan Tebu}

Data profil guludan sangat diperlukan untuk mendisain dimensi dan ketinggian rangka dari mesin pencacah serasah tebu, untuk menghidari benturan antara mesin pencacah dengan tinggi guludan. Sedangkan data lebar jarak tanaman diperlukan untuk lebar pengambilan serasah dan posisi pijakan roda agar bisa bergerak sesuai dengan alur. Berdasarkan hasil pengukuran diperoleh data bahwa lebar guludan $120 \mathrm{~cm}$, jarak antar tanaman $120 \mathrm{~cm}$, tinggi guludan $20 \mathrm{~cm}$ (Gambar 6).
Lebar mesin pencacah yang dirancang adalah $240 \mathrm{~cm}$ dua kali jarak tanaman. Hal ini karena mempertimbangkan pemasangan alat lain pada mesin pencacah seperti lebar gear box, lebar sprocket dan lebar bantalan. Selain itu posisi roda harus masuk pada alur guludan. Adapun lebar unit pengambil dirancang $60 \mathrm{~cm}$ setengah dari jarak tanaman dengan harapan agar serasah yang ada di lahan bisa terambil dengan baik. Mengingat unit pengambil terintegrasi dengan unit pencacah maka nilai lebar unit pengambil tersebut merupakan dasar dalam menentukan panjang silinder penjepit ataupun silinder pencacah.

\section{KESIMPULAN DAN SARAN}

1. Hasil pengukuran terhadap prodil guludan tanah diperoleh data lebar guludun $120 \mathrm{~cm}$, jarak tanaman $120 \mathrm{~cm}$ dan tinggi guludan 20 $\mathrm{cm}$.

2. Kerapatan Kamba serasah tebu $7,71 \mathrm{~kg} / \mathrm{cm}^{3}$, kadar air batang adalah $84.1 \%$, rata - rata kadar air pucuk adalah $15.7 \%$, dan rata - rata kadar air daun adalah $16.9 \%$.

3. Karakteristik fisik pucuk : panjang rata-rata pucuk $162.5 \mathrm{~cm}$, jumlah rata-rata daun per pucuk 4.1 lembar, lebar daun rata-rata $5.0 \mathrm{~cm}$, tebal daun rata-rata $0.3 \mathrm{~mm}$, diameter pangkal pucuk rata-rata $21.3 \mathrm{~mm}$, dan berat pucuk 57.3 gram.

4. Karakteristik daun : panjang daun $161.1 \mathrm{~cm}$, lebar pangkal daun $4.4 \mathrm{~cm}$, lebar tengah daun $4.1 \mathrm{~cm}$, lebar ujung daun $3.9 \mathrm{~cm}$, tebal daun $0.3 \mathrm{~mm}$, dan berat daun 8.9 gram.

\section{DAFTAR PUSTAKA}

Ditjenbun. 2007. Potensi dan Prospek Pabrik Gula di Luar Jawa. Makalah presentasi di Seminar Gula Nasioanal Perhimpunan Teknik Pertanian (PERTETA) di Makassar, 4 Agustus 2007. 
Persson, Sverker. 1987. Mechanics of Cutting Plant Material. An ASAE Monograph Number 7 in a series published by American Society of Agricultural Engineers. Michigan.

Robert Worsing. 1995 Rural Rescue and Emergency Care. American Academy of orthopaedic Surgeons.

Sitkey, G. 1986. Mechanics Of Agricultural Matrial. ELSEVIER, Amsterdam.

Srivastava.1993 Engineering Prinsiple of Agricultural Machine.ASAE Textbook Number 6 Published by American Society of Agricultural Engineers.

Toharisman, A., 1991. Pengelolaan Tebu Berkelanjutan. Pusat Penelitian Perkebunan Gula Indonesia (P3GI). 
Kondisi Lahan Kebun Tebu.... (Wahyu KS, I Nengah S dan Joko W) 